\title{
Spectroscopic determination of alkyl resorcinol concentration in hydroxyapatite composite
}

\author{
Won-Geun Yang ${ }^{1}$, Jeong-Hyon $\mathrm{Ha}^{2}$, Seong-Gon $\mathrm{Kim}^{3}$ and Weon-Sik Chae ${ }^{\text {* }^{*}}$
}

\begin{abstract}
Background: Recently, alkyl resorcinol compounds showed remarkable improvements on dental implant restoration as well as anaesthetic, antiseptic, and anthelmintic applications. In this study, we prepared biologically functional composition of 4-hexylresorcinol (4HR)-loaded hydroxyapatite (HA).

Findings: Attenuated total reflectance (ATR) Fourier-transform infrared (FT-IR) spectroscopy fully assigned vibrational absorptions of 4-hexylresorcinol as well as the HA. The absorption coefficient of 4HR aqueous solution is estimated to be $1393 \pm 61 \mathrm{~cm}^{-1} \mathrm{M}^{-1}$ at highly diluted concentration. The 4HR was loaded with $0.018 \%$ (wt/wt) in the 4HR-HA composite.

Conclusions: We quantitatively determined the micromolar concentration of 4HR loaded in the composite based on ultraviolet-visible (UV-Vis) absorption spectroscopy.
\end{abstract}

Keywords: 4-hexylresorcinol, Hydroxyapatite, ATR-FT-IR, UV-Vis

\section{Findings}

\section{Background}

Hydroxyapatite (HA) is the major component of bone material and a hexagonally packed crystal with hydroxyl end members (Pleshko et al. 1991). HA analogue materials have been extensively developed through a variety of chemical and physical routes (Ferraz et al. 2004; Bouyer et al. 2000; Cengiz et al. 2008). One of tremendous use of HA is bone grafting application via coating metallic dental implant surface, which stimulates bone healing and therefore improves implant integration rate and strength (Cook et al. 1987; Lange and Donath 1989). According to previous reports, however, HA-coated dental implants have often failed because of bacterial infection (Chang and Tanaka 2002; Destainville et al. 2003; Coates 2000). Hence, infection-resistant HA coating with bioinert antiseptic function is of great interest. Recently, a 4-hexylresorcinol (4HR)-treated HA-titanium dental implant showed significant improvement in both

\footnotetext{
* Correspondence: wschae@kbsi.re.kr

${ }^{1}$ Analysis Research Division, Daegu Center, Korea Basic Science Institute,

Daegu 41566, Republic of Korea

Full list of author information is available at the end of the article
}

bone formation and bone-to-implant contact after implant surgery (Kim et al. 2011a).

Alkyl resorcinols, natural non-isoprenoid phenolic lipids found in plants (Tyman 1979), have attracted much attention due to a variety of biologic functions, such as being nonspecific antioxidants, antimutagens, and regulatory molecules (Kim et al. 2011b). Hexylresorcinol is an organic compound with well-known anaesthetic, antiseptic, and anthelmintic properties (Wilson and Gisvold 1954). By now, hexylresorcinol have been used in a variety of application areas, such as skincare products with anti-aging function, food additive with estrogenic activity (Amadasi et al. 2009), and anti-cancer activity by inhibiting NF- $\kappa B$ (Kim et al. 2011a). Hexylresorcinol inhibits the formation of graft-induced foreign body giant cells (Kweon et al. 2014). Therefore, hexylresorcinol has been used for bone substitute-related tissue engineering (Lee et al. 2015).

Several routes have been tried to deposit $4 \mathrm{HR}$ on the hydrophilic HA; however, precise control of $4 \mathrm{HR}$ loading amount is still challenging because of the amphiphilic character of 4HR (Kim et al. 2011b). Therefore, quantitative determination of the loading amount is importantly required to further optimize

\section{Springer}


composite materials with a demanded function (Kweon et al. 2014; Lee et al. 2015). In this study, solution-processed 4HR-loaded HA composite were quantitatively characterized using Fourier-transform infrared (FT-IR) and ultraviolet-visible (UV-Vis) absorption spectroscopies. Infinitesimal amount of 4HR, which was loaded on HA powder, could be detected and precisely estimated based on UV-Vis absorption spectroscopy. Additionally, we entirely assigned IR absorption peaks of $4 \mathrm{HR}$ for the first time.

\section{Material and methods}

\section{Chemicals and materials}

Hydroxyapatite (reagent grade) and 4-hexylresorcinol (98\%) were used as received from Sigma Aldrich. 4HR-loaded HA composite (4HR-HA) was prepared in aqueous medium for FT-IR and UV-Vis absorption study. $0.5 \mathrm{~g}$ of hydroxyapatite was mixed with $50 \mathrm{ml}$ of $0.1 \mathrm{M}$ 4-hexylresorcinol aqueous solution and then stirred at $200 \mathrm{rpm}$ for $1 \mathrm{~h}$. The suspension was finally filtered and dried for $24 \mathrm{~h}$.

\section{Spectroscopic characterization}

FT-IR absorption spectra were obtained using a Fouriertransform spectrometer (Vertex 80, Bruker Optics) equipped with an attenuated total reflectance (ATR) accessory (MIRacle, PIKE technologies). Spectrum was recorded in the spectral range of 600 to $4000 \mathrm{~cm}^{-1}$ at a resolution of $2 \mathrm{~cm}^{-1}$ with a mercury cadmium telluride detectors (MCT detector), and 128 repeated scans were averaged for each spectrum. The UV-Vis absorption spectra were obtained using a spectrophotometer (S-3100, Scinco).

\section{Results and discussion}

We performed FT-IR absorption study to evaluate the loading amount of $4 \mathrm{HR}$ in $\mathrm{HA}$ composite powder. Figure 1 shows IR absorption spectrum of the bare HA powder, which presented the phosphate band between 900 and $1200 \mathrm{~cm}^{-1}$. In Fig. 1, there are $\mathrm{PO}_{4}^{3-} v_{1}$ mode at $962 \mathrm{~cm}^{-1}$ (Chang and Tanaka 2002; Kim et al. 2011a; Han et al. 2006) and $\mathrm{PO}_{4}^{3-} v_{3}$ mode at 1028 (Chang and Raynaud et al. 2002; Destainville et al. 2003; Kim et al. 2011b; Han et al. 2006; Kim et al. 2012), 1088 (Chang and Raynaud et al. 2002; Destainville et al. 2003; Kim et al. 2011a; Han et al. 2006; Kim et al. 2012), and $870 \mathrm{~cm}^{-1}$ (Destainville et al. 2003; $\mathrm{Han}$ et al. 2006) band for $\mathrm{HPO}_{4}^{3-}$ and labile $\mathrm{PO}_{4}^{3-}$ mode at $632 \mathrm{~cm}^{-1}$ (Chang and Tanaka 2002; Kim et al. 2011b). Adsorbed water shows relatively wide stretching vibrational absorption in mid-IR region from 3600 to $3000 \mathrm{~cm}^{-1}$ with a distinct peak at $3572 \mathrm{~cm}^{-1}$. The absorption peak observed at $3572 \mathrm{~cm}^{-1}$ indicates the presence of the $-\mathrm{OH}$ group (Kim et al. 2011a;

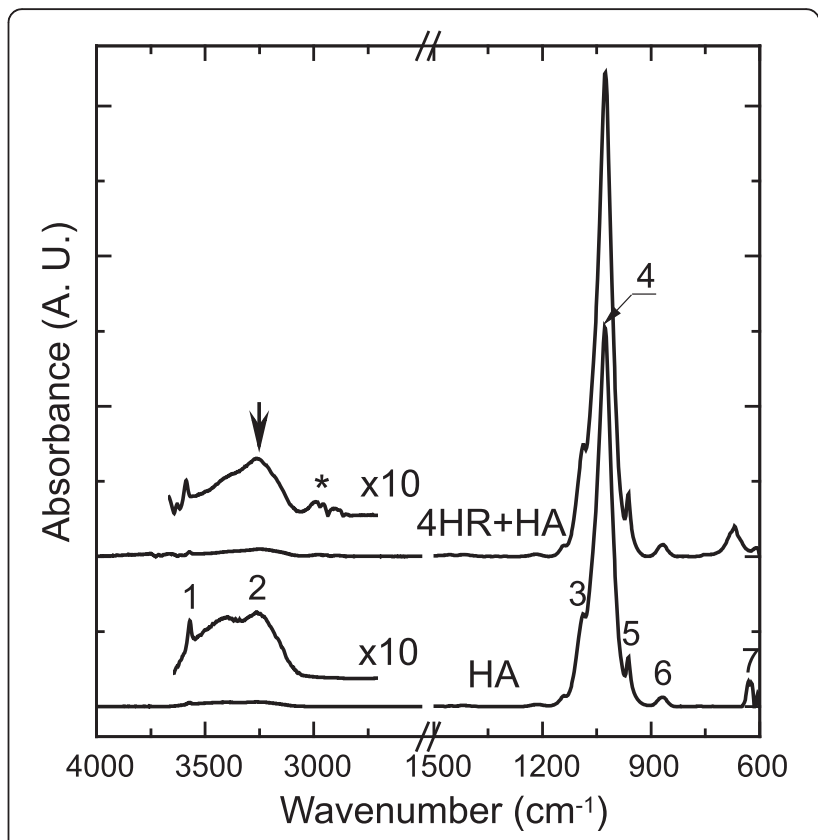

Fig. 1 FT-IR absorption spectra of the HA and the 4HR-loaded HA

Raynaud et al. 2002; Han et al. 2006; Kim et al. 2012). Summarized data are shown in Table 1.

Figure 2 shows the FT-IR absorption spectrum of 4-hexylresorcinol. The vibrational absorption peak at $3039 \mathrm{~cm}^{-1}$ corresponds to the aromatic hydrocarbon, and the absorbance peaks at 3340 and $3419 \mathrm{~cm}^{-1}$ are assigned to hydrogen bonding between hydroxyl groups in benzene ring (Kim et al. 2012). The characteristic $\mathrm{C}-\mathrm{H}$ stretching vibrations for saturated aliphatic species occur between 3000 and $2800 \mathrm{~cm}^{-1}$, and the corresponding simple bending vibrations nominally occur between 1500 and $1300 \mathrm{~cm}^{-1}$. The absorption peaks at 2960,2922, 2873, and $2856 \mathrm{~cm}^{-1}$ are corresponding to the well-known asymmetric and

Table 1 Characteristic IR absorptions of hydroxyapatite

\begin{tabular}{|c|c|c|c|}
\hline Wavenumber $\left(\mathrm{cm}^{-1}\right)$ & Bond & Position & Reference \\
\hline 3572 & $\mathrm{OH}^{-}$ & 1 & $\begin{array}{l}\text { (Kim et al. 2011a; Raynaud } \\
\text { et al. 2002; Han et al. 2006; } \\
\text { Kim et al. 2012) }\end{array}$ \\
\hline $3000 \sim 3600$ & $\mathrm{H}_{2} \mathrm{O}$ & 2 & (Meejoo et al. 2006) \\
\hline 1028,1088 & $\mathrm{PO}_{4}^{3-}(\mathrm{V} 3)$ & 3,4 & $\begin{array}{l}\text { (Chang \& Raynaud et al. } \\
\text { 2002; Destainville et al. } \\
\text { 2003; Kim et al. 2011b; Han } \\
\text { et al. 2006; Kim et al. 2012) }\end{array}$ \\
\hline 962 & $\mathrm{PO}_{4}^{3-}(\mathrm{v} 1)$ & 5 & $\begin{array}{l}\text { (Chang and Tanaka 2002; } \\
\text { Kim et al. 2011a; Han et al. } \\
\text { 2006) }\end{array}$ \\
\hline 870 & $\mathrm{HPO}_{4}^{3-}$ & 6 & $\begin{array}{l}\text { (Destainville et al. 2003; } \\
\text { Han et al. 2006) }\end{array}$ \\
\hline 632 & Labile $\mathrm{PO}_{4}^{3-}$ & 7 & $\begin{array}{l}\text { (Chang and Tanaka 2002; } \\
\text { Kim et al. 2011b) }\end{array}$ \\
\hline
\end{tabular}




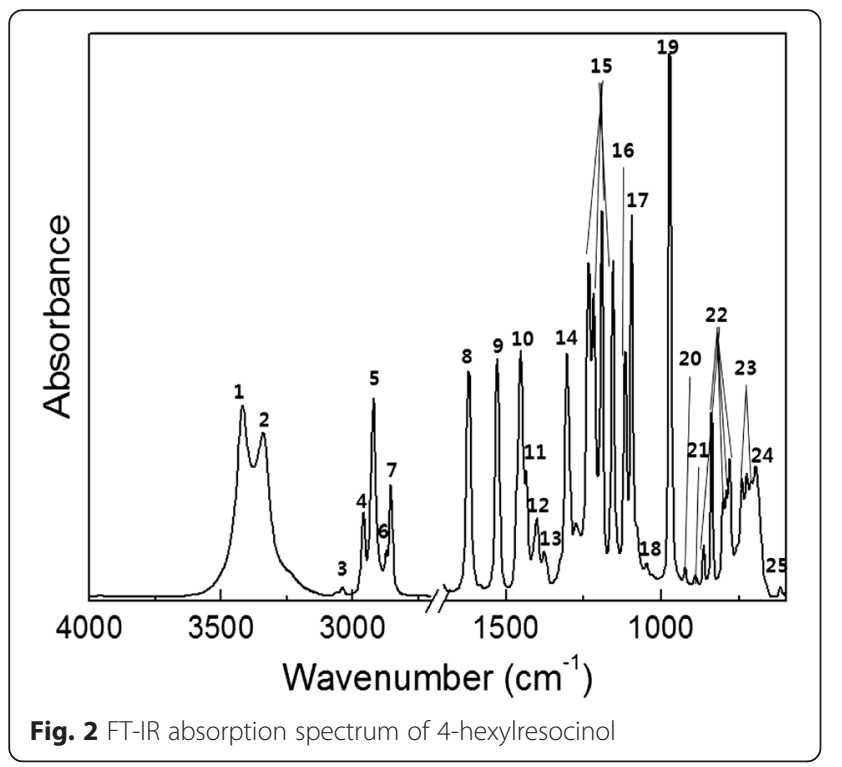

Table 2 Characteristic IR absorptions of 4-hexylresorcinol

\begin{tabular}{|c|c|c|c|}
\hline Wavenumber $\left(\mathrm{cm}^{-1}\right)$ & Bond & Position & Reference \\
\hline 3340,3419 & Hydrogen bonded $\mathrm{OH}$ stretching & 1,2 & (Kim et al. 2012) \\
\hline 3039 & Aromatic $\mathrm{CH}$ stretching & 3 & (Kim et al. 2012) \\
\hline 2960 & Aliphatic $\mathrm{CH}_{3}$ asymmetric stretching & 4 & (Coates 2000; Kim et al. 2012) \\
\hline 2922 & Aliphatic $\mathrm{CH}_{2}$ asymmetric stretching & 5 & (Coates 2000; Kim et al. 2011a; Kim et al. 2012) \\
\hline 2873 & Aliphatic $\mathrm{CH}_{3}$ symmetric stretching & 6 & (Coates 2000; Kim et al. 2012) \\
\hline 2856 & Aliphatic $\mathrm{CH}_{2}$ symmetric stretching & 7 & (Coates 2000; Kim et al. 2011b; Kim et al. 2012) \\
\hline 1620,1527 & Aromatic ring $\mathrm{C}-\mathrm{C}$ stretching & 8,9 & (Coates 2000) \\
\hline 1452 & Aliphatic $\mathrm{CH}_{2}$ bending & 10 & (Coates 2000; Krimm et al. 1956) \\
\hline 1435 & Aliphatic $\mathrm{CH}_{3}$ asymmetric bending & 11 & (Coates 2000) \\
\hline 1398 & Phenolic $\mathrm{OH}$ bending & 12 & (Coates 2000) \\
\hline 1377 & Aliphatic $\mathrm{CH}_{3}$ symmetric bending & 13 & (Coates 2000; Krimm et al. 1956) \\
\hline 1304 & Aliphatic $\mathrm{CH}_{2}$ wagging (disordered phase) & 14 & (Krimm et al. 1956) \\
\hline 1234, 1217, 1192, 1155 & C-O stretching & 15 & (Silverstein et al. 1991; Choo et al. 2011) \\
\hline 1116 & $\mathrm{C}-\mathrm{C}-\mathrm{H}$ bending & 16 & (Hallos 1984) \\
\hline 1095 & C-C stretching & 17 & (Krimm et al. 1956; Frost et al. 2007) \\
\hline 1047 & OH deformation stretching & 18 & (Evanoff and Chumanov 2004) \\
\hline 974 & $\mathrm{CH}_{2}$ wagging or twisting & 19 & (Kozubek and Tyman 1999) \\
\hline 924 & C $-\mathrm{O}$ stretching & 20 & (Cui et al. 2013; Gómez-Sánchez et al. 2011) \\
\hline 891 & $\mathrm{CH}_{3}$ rocking & 21 & (Krimm et al. 1956) \\
\hline $864,839,800,791,779$ & Aromatic C-H out-of-plane bending & 22 & (Coates 2000; Silverstein et al. 1991) \\
\hline 725,740 & $\mathrm{CH}_{2}$ rocking & 23 & (Coates 2000; Krimm et al. 1956) \\
\hline 696 & Out-of-plane ring $\mathrm{C}=\mathrm{C}$ bending & 24 & (Silverstein et al. 1991) \\
\hline 617 & OH out-of-plane bending & 25 & (Silverstein et al. 1991) \\
\hline
\end{tabular}

symmetric stretching modes of aliphatic hydrocarbons (Coates 2000; Kim et al. 2011b; Kim et al. 2012; Krimm et al. 1956). Aromatic ring stretching vibration was observed at 1620 and $1527 \mathrm{~cm}^{-1}$ (Coates 2000). The absorption at $1452 \mathrm{~cm}^{-1}$ and the two weak peaks at 1435 and $1377 \mathrm{~cm}^{-1}$ are corresponding to the bending mode and the asymmetric and symmetric stretching modes of the aliphatic hydrocarbons, respectively (Coates 2000; Krimm et al. 1956). The phenolic $\mathrm{OH}$ bending mode of phenol species occurs at $1398 \mathrm{~cm}^{-1}$ (Coates 2000). The absorption peak at $1304 \mathrm{~cm}^{-1}$ reveals aliphatic $\mathrm{CH}_{2}$ wagging mode in disordered phase (Krimm et al. 1956). The intense absorptions at 1234, 1217, 1192, 1155, and $924 \mathrm{~cm}^{-1}$ are responsible for the $\mathrm{C}-\mathrm{O}$ stretching modes in phenol species (Silverstein et al. 1991; Choo et al. 2011). The absorption peak at $1116 \mathrm{~cm}^{-1}$ can be assigned to the $\mathrm{C}-\mathrm{C}-\mathrm{H}$ bending mode (Cui et al. 2013). The absorption peaks at 1095, 974, 891 and 740, and $725 \mathrm{~cm}^{-1}$ were assigned to the $\mathrm{C}-\mathrm{C}$ stretching mode (Krimm et al. 1956; Gómez-Sánchez et al. 2011), the $\mathrm{CH}_{2}$ wagging or twisting mode (Hallos 1984), the $\mathrm{CH}_{3}$ rocking mode (Krimm et al. 1956), and the $\mathrm{CH}_{2}$ rocking mode (Coates 2000; Krimm et al. 1956) of 
aliphatic hydrocarbons, respectively. The absorption peaks at $1047 \mathrm{~cm}^{-1}$ are for the $\mathrm{OH}$ deformation stretching mode (Frost et al. 2007). The IR absorption peaks at $864,839,800,791$, and $779 \mathrm{~cm}^{-1}$ can be assigned to the aromatic $\mathrm{C}-\mathrm{H}$ out-of-plane bending mode (Coates 2000; Silverstein et al. 1991). The peaks at 696 and $617 \mathrm{~cm}^{-1}$ are assigned to the out-of-plane ring $\mathrm{C}=\mathrm{C}$ bending and $\mathrm{OH}$ out-of-plane bending modes, respectively (Silverstein et al. 1991). Detailed assignments are fully summarized in Table 2 .

FT-IR spectrum of the 4HR-HA composite showed the majority absorptions for the HA without any distinct change (Fig. 1). Additionally, very weak $\mathrm{C}-\mathrm{H}$ stretching absorption corresponding to the $4 \mathrm{HR}$ is observed in the region of $2800-3000 \mathrm{~cm}^{-1}$ (asterisk indicated). After 4-hexylresorcinol treatment, the 4HR-HA composite showed enhanced absorption at $3260 \mathrm{~cm}^{-1}$ (arrow indicated). This can be attributed to hydrogen bonding between $4 \mathrm{HR}$ and HA. However, it is still ambiguous to precisely estimate $4 \mathrm{HR}$ concentration in this composite.

From the absorption spectrum in the UV-Vis region (Fig. 3), the 4HR aqueous solution showed the characteristic absorption at $\sim 270 \mathrm{~nm}$, corresponding to $\pi-\pi^{*}$ electronic transition (Silverstein et al. 1991). As a function of concentration, absorption coefficient value is decreased (inset of Fig. 3a). According to the previous reports, alkyl resorcinols with a long hydrocarbon tail easily tend to aggregate to form micelles in an aqueous medium (Kozubek and Tyman 1999), hence, inevitably reducing absorption efficiency. Therefore, the absorption coefficient of $4 \mathrm{HR}$ aqueous solution is estimated at a highly diluted concentration, which enabled the absorption coefficient of $1393 \pm$ $61 \mathrm{~cm}^{-1} \mathrm{M}^{-1}$.

The additional absorption was also shown at $\sim 430 \mathrm{~nm}$, which is attributed to the scattering of HA powder. A colloidal powder suspension typically scatters light in the visible region. The scattering absorption can vary as a function of colloidal particle size (Evanoff and Chumanov 2004; Chae et al. 2009). In this study, the bulk HA powder showed a broad scattering with a maximum at $535 \mathrm{~nm}$. As the $\mathrm{HA}$ was treated with $4 \mathrm{HR}$, the scattering peak was observed at $430 \mathrm{~nm}$. This blue-shifted scattering seems to be attributed to the fragmentation of the HA powder after $4 \mathrm{HR}$ treatment.

It is noteworthy that the absorption spectrum of the 4HR-loaded HA powder clearly reveals the presence of 4HA. The measured absorbance of 0.0065 is corresponding to $4.7 \mu \mathrm{M}$ concentration and $3.5 \mu \mathrm{g} 4 \mathrm{HR}$ in a standard cuvette. Regarding the total 4HR-HA composite powder mass of $19 \mathrm{mg}$ for the UV-Vis measurement, the $4 \mathrm{HR}$ was loaded with $0.018 \%$ (wt/wt) in the $4 \mathrm{HR}-\mathrm{HA}$
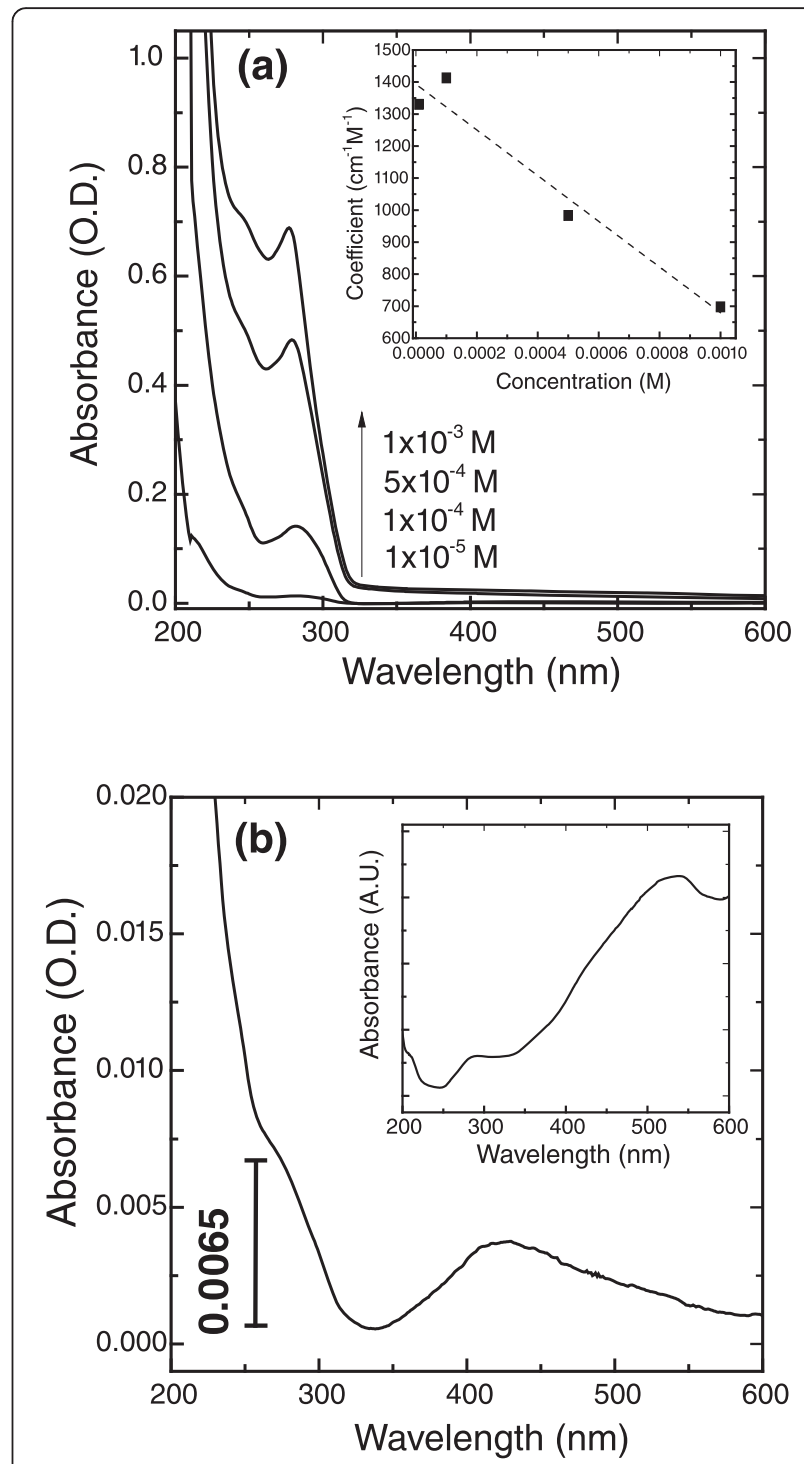

Fig. 3 UV-Vis absorption spectra of the 4HR (a) and the 4HR-loaded HA composite powder (b). Inset of $\mathbf{a}$ is the absorption coefficients of $4 \mathrm{HR}$ as a function of concentration. Inset of $\mathbf{b}$ is the absorption spectrum of the HA powder aqueous mixture $(5 \mathrm{mg} / \mathrm{ml})$

composite. This small loading amount reasonably explains why IR spectroscopy need to take extra special care on sampling to determine the 4HR concentration even in ATR mode with a typical detection limit of $\sim 0.1 \mathrm{wt} \%$ or $10^{-4} \mathrm{M}$.

\section{Conclusions}

We estimated an amount of 4-hexylresorcinol compound from its composite form with hydroxyapatite using FT-IR and UV-Vis absorption spectroscopies. Because of the majority IR absorptions of HA, the precise estimation of $4 \mathrm{HR}$ concentration in the 4HR-HA composite is a little ambiguous using FT-IR spectroscopy. On the other hand, the 4HR-HA composite showed 
clear absorption for 4HR in the ultraviolet region. Based on UV-Vis absorption spectroscopy, we effectively estimated the micromolar quantity of the loaded $4 \mathrm{HR}$ in the 4HR-HA composite.

\section{Competing interests}

All authors declare that they have no competing interests.

\section{Authors' contributions}

WSC designed the study. WGY and WSC performed research. WGY and JHH carried out FT-IR analysis. WGY and WSC carried out UV-Vis absorption analysis. WGY, SGK, and WSC wrote the manuscript. All authors read and approved the final manuscript.

\section{Acknowledgements}

This research was supported by Basic Science Research Program through the National Research Foundation of Korea (NRF) funded by the Ministry of Education (NRF-2015R1D1A1A01058935).

\section{Author details}

${ }^{1}$ Analysis Research Division, Daegu Center, Korea Basic Science Institute, Daegu 41566, Republic of Korea. ${ }^{2}$ Space-Time Resolved Molecular Imaging Research Team, Korea Basic Science Institute, Seoul 02855, Republic of Korea. ${ }^{3}$ Department of Oral and Maxillofacial Surgery, College of Dentistry, Gangneung-Wonju National University, Gangneung 25457, Republic of Korea.

Received: 4 February 2016 Accepted: 8 March 2016

Published online: 14 March 2016

\section{References}

Amadasi A, Mozzarelli A, Meda C, Maggi A, Cozzini P. Identification of xenoestrogens in food additives by an integrated in silico and in vitro approach. Chem Res Toxicol. 2009;22:52-63.

Bouyer E, Gitzhofer F, Boulos MI. Morphological study of hydroxyapatite nanocrystal suspension. J Mater Sci: Mater Med. 2000;11:523-31.

Cengiz B, Gokce Y, Yildiz N, Aktas Z, Calimli A. Synthesis and characterization of hydroxyapatite nanoparticle. Colloids Surf A: Physicochem Eng Aspects. 2008; 322:29-33.

Chae WS, Kershner RJ, Braun PV. Fabrication of 50 to $1000 \mathrm{~nm}$ monodisperse ZnS colloids. Bull Korean Chem Soc. 2009;30:129-32.

Chang MC, Tanaka JZ. FT-IR study for hydroxyapatite/collagen nanocomposite cross-linked by glutaraldehyde. Biomater. 2002;23:4811-8.

Choo ESG, Tang XS, Sheng Y, Shuter B, Xue JM. Controlled loading of superparamagnetic nanoparticles in fluorescent nanogels as effective T2-weighted MRI contrast agents. J Mater Chem. 2011;21:2310-9.

Coates J. In Encyclopedia of Analytical Chemistry, Interpretation of Infrared Spectra, A Practical Approach. Chichester: John Wiley \& Sons; 2000.

Cook SD, Kay JF, Thomas KA. Interface mechanics and histology of titanium and HA-coated titanium for dental implant applications. Int J Oral Maxillofac Implants. 1987:2:15-22.

Cui CZ, Park DH, Kim JY, Joo JS, Ahn DJ. Oligonucleotide assisted light-emitting Alq3 microrods: energy transfer effect with fluorescent dyes. Chem Commun. 2013:49:5360-2.

Destainville A, Champion E, Bernache-Assollant D, Laborde E. Synthesis, characterization and thermal behavior of apatitic tricalcium phosphate. Mater Chem Phys. 2003;80:269-77.

Evanoff DD, Chumanov G. Size-controlled synthesis of nanoparticles. 2. Measurement of extinction, scattering, and absorption cross sections. J Phys Chem B. 2004;108:13957-62.

Ferraz MP, Monteiro FJ, Manuel CM. Hydroxyapatite nanoparticles: a review of preparation methodologies. J Appl Biomater Biomech. 2004;2:74-80.

Frost RL, Wain DL, Martens WN, Reddy BJ. Vibrational spectroscopy of selected minerals of the rosasite group. Spectrochim Acta Part A: Mol Biomol Spectrosc. 2007;66:1068-74

Gómez-Sánchez E, Simon S, Koch LC, Wiedmann A, Weber T, Mengel M. ATR-FTIR spectroscopy for the characterization of magnetic tape materials. e-Preserv Sci. 2011;8:2-9.

Hallos RS. A "chain fold band" in the infrared spectra of nylon 6. J Appl Polym Sci. 1984;29:3907-14.
Han JK, Song HY, Saito FM, Lee BT. Synthesis of high purity nano-sized hydroxyapatite powder by microwave-hydrothermal method. Mater Chem Phys. 2006;99:235-9.

Kim SG, Hahn BD, Park DS, Lee YC, Choi EJ, Chae WS, et al. Aerosol deposition of hydroxyapatite and 4-hexylresorcinol coatings on titanium alloys for dental implants. J Oral Maxillofac Surg. 2011a;69:354-63.

Kim SG, Lee SW, Park YW, Jeong JH, Choi JY. 4-hexylresorcinol inhibits NF-KB phosphorylation and has a synergistic effect with cisplatin in KB cells. Oncol Rep. 2011b;26:1527-32.

Kim MK, Park YT, Kim SG, Park YW, Lee SK, Choi WS. The effect of a hydroxyapatite and 4-hexylresorcinol combination graft on bone regeneration in the rabbit calvarial defect model. Korean Assoc Maxillofac Plast Reconstr Surg. 2012;34: 377-83.

Kozubek A, Tyman JHP. Resorcinolic lipids, the natural non-isoprenoid phenolic amphiphiles and their biological activity. Chem Rev. 1999;99:1-25.

Krimm SCYL, Liang CY, Sutherland GBBM. Infrared spectra of high polymers. II. Polyethylene. J Chem Phys. 1956;25:549-62.

Kweon H, Kim SG, Choi JY. Inhibition of foreign body giant cell formation by 4 -hexylresorcinol through suppression of diacylglycerol kinase delta gene expression. Biomater. 2014;35:8576-84.

Lange GL, Donath K. Interface between bone tissue and implants of solid hydroxyapatite or hydroxyapatite-coated titanium implants. Biomater. 1989;10:121-5.

Lee SW, Um IC, Kim SG, Cha MS. Evaluation of bone formation and membrane degradation in guided bone regeneration using a 4-hexylresorcinol-incorporated silk fabric membrane. Maxillofac Plast Reconstr Surg. 2015;37:32-6.

Meejoo S, Maneeprakorn W, Winotai P. Phase and thermal stability of nanocrystalline hydroxyapatite prepared via microwave heating. Thermochim Acta. 2006:447:115-20.

Pleshko N, Boskey A, Mendelsohn R. Novel infrared spectroscopic method for the determination of crystallinity of hydroxyapatite minerals. Biophys J. 1991;60: 786-93.

Raynaud S, Champion E, Bernache-Assollant D, Thomas P. Calcium phosphate apatites with variable $\mathrm{Ca} / \mathrm{P}$ atomic ratio I. Synthesis, characterisation and thermal stability of powders. Biomater. 2002;23:1065-72.

Silverstein RM, Bassler GC, Morrill TC. In Spectrometric identification of organic compounds, Infrared Spectrometry. New York: John Wiley \& Sons; 1991

Tyman JHP. Non-isoprenoid long chain phenols. Chem Soc Rev. 1979;8:499-537.

Wilson CO, Gisvold O. Textbook of organic medicinal and pharmaceutical chemistry. Philadelphia: Lippincott; 1954. 237-262

\section{Submit your manuscript to a SpringerOpen ${ }^{\mathcal{O}}$ journal and benefit from:}

- Convenient online submission

- Rigorous peer review

- Immediate publication on acceptance

- Open access: articles freely available online

- High visibility within the field

- Retaining the copyright to your article

Submit your next manuscript at $\boldsymbol{s p r i n g e r o p e n . c o m ~}$ 